\title{
Jelgersma's vroege ideeën over het ontstaan van epilepsie
}

Enige tijd geleden trof de auteur van deze bijdrage bij toeval een in I888 door G. Jelgersma geschreven brief aan. Deze Gerbrandus Jelgersma werd elf jaar later aan de Leidse universiteit benoemd tot de eerste hoogleraar psychiatrie in ons land. In de teruggevonden brief zette Jelgersma zijn gedachten uiteen over de mogelijke oorzaken van epilepsie. Hij beschouwde deze als een psychische ziekte, gerelateerd aan psychosen en gepaard gaande met karakterveranderingen en dementie.

Tot het uitbreken van de recente coronapandemie was de bibliofiele schrijver van dit artikel een regelmatige bezoeker van boekenmarkten. Enkele jaren geleden vond hij op de jaarlijks plaatsvindende boekenmarkt van Deventer een exemplaar van de in 1943 door Prof. Dr. Eugène Carp gepubliceerde biografie van Prof. Dr. Gerbrandus Jelgersma. Carp was in 1930 Jelgersma in Leiden opgevolgd als hoogleraar psychiatrie.

\section{Teruggevonden brief}

Voorin het boekje bleek zich een op 3 februari I 888 gedateerde brief te bevinden die was geschreven en ondertekend door G. Jelgersma, de persoon over wie de biografie handelde. Hoe het schrijven daar terecht kwam, is een raadsel. De inhoud van Jelgersma's brief betrof zijn antwoord op een door een Rotterdamse collega aan hem gestelde vraag/vragen over de ontstaanswijze van epilepsie. Dit zeer waarschijnlijk naar aanleiding van het door Jelgersma op 7 januari I 888 in het Nederlandsch Tijdschrift voor Geneeskunde gepubliceerde artikel 'Over de pathogenese der epilepsie'. Hierin beschreef hij de macro- en microscopische hersenbevindingen bij een achttal in het krankzinnigengesticht Meerenberg te Santpoort overleden epilepsielijders. Jelgersma was daar indertijd werkzaam als arts pathologische anatomie (prosector). Op de volgende pagina laten we een transcriptie van de teruggevonden brief volgen. De tussen [ ] geplaatste aanvullingen zijn van de schrijver van dit artikel.

\section{Wie was Jelgersma?}

De uit een Fries predikantengeslacht stammende Gerbrandus Jelgersma (I859- I942) studeert in I885 af als arts aan de Universiteit van Amsterdam. Het 'meisje' waarover hij aan het eind van zijn brief schrijft, zal de Schiedamse koopmansdochter Elisabeth Henrica Nelida Ris geweest zijn met wie hij op 2I december I888 trouwt (www.genealogieonline.nl). Al tijdens zijn studie geneeskunde voelt Jelgersma zich sterk aangetrokken tot de psy-

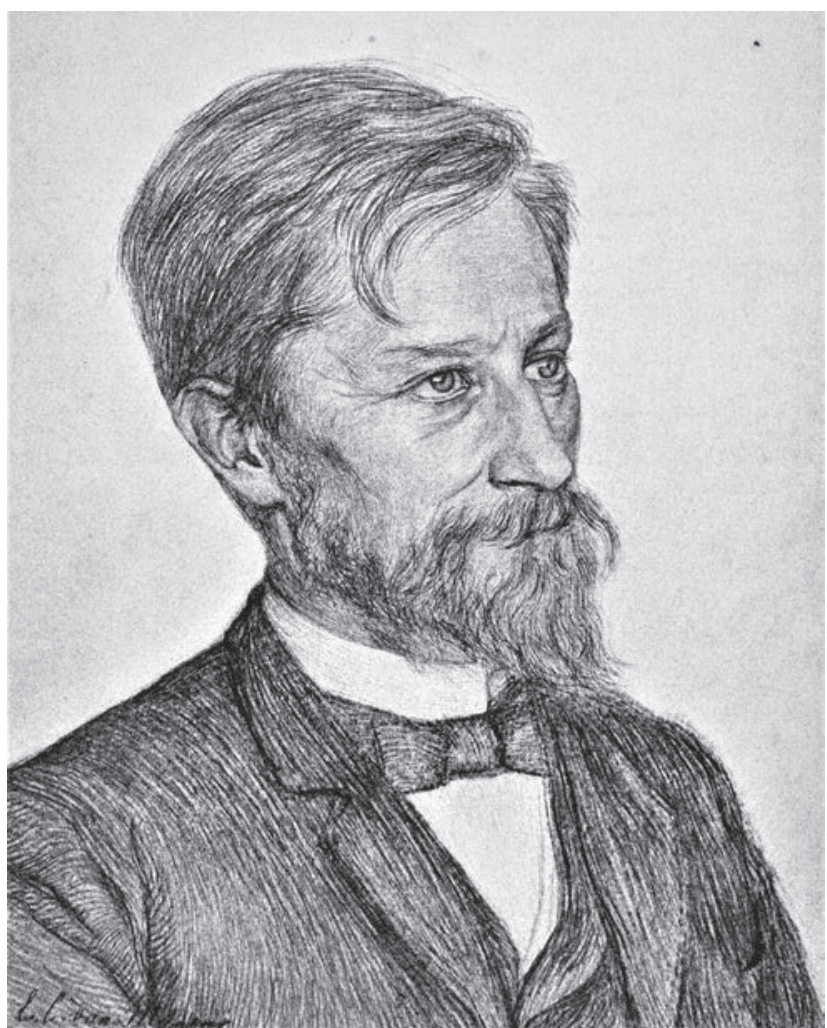

Portret van Prof. Dr. G. Jelgersma, 1905, tekening Betsy van Manen (Nederlands Instituut voor Kunstgeschiedenis, Den Haag)

chiatrie. Dit resulteert twee jaar na zijn afstuderen tot de bovengenoemde aanstelling als prosector in Meerenberg. Vanaf I 885 assisteert hij daar al bij obducties, eerst als student, later als arts.

In I894 volgt Jelgersma's benoeming tot geneesheerdirecteur van het Sanatorium voor Zenuwlijders De Vogelen Plantentuin in Velp waar hij de speurtocht naar hersenafwijkingen bij zijn overleden patiënten voortzet. In I897 krijgt hij samen met W.H. Cox, als arts verbonden aan het krankzinnigengesticht Brinkgreve in Deventer, een eredoctoraat van de Universiteit van Utrecht. Dit voor hun beider patholoog-anatomische bevindingen in de hersenen van psychiatrische patiënten. 
Meerenberg 3 Februari 1888

Amice

In antwoord op je brief zou ik je een lang epistel moeten scbrijven om je mijne opinie over de patbogenese der epilepsie mede [te] deelen, ik beb daar voor ecbter op 't oogenblik werkelijk de tijd niet en zal je daarom maar een paar dingen sebrijven. Mijn vorig stukje [artikel NTVG, 1888] Gebandelde bijna uitsluitend de patbologische anatomie, is bad voor de kliniek nog te weinig cigen waarnemingen. Is wil je daarover mijne opinie gaame mededeelen. Epilepsie als alndoening van bet grijze oppervlak der bersensebors beschouw ik als een psychische ziekte met daaraan de plaatselijk sterk ontwikkelde sebors,'t corpus striatum en lentiforme ook deelneemen komt mij wel waarsebijnlijk voor, is echter nog moeilijk te bewijzen. De nauwe verwantsebap tot de psychosen is bij de epilepsie klinisch zeer duidelijk, $1^{e}$ door de psychische versebijnselen die zich dikwijls na, in plaats van of voor een aanval vertoonen, $2^{e}$ de dementie, $3^{e}$ de karakterverandering, bet egoisme enz. Na verwant met de epileptische [patieinten] zijn de sommige misdadigers. De epileptiscbe aanval doet echter waarsebijnlijk niet steeds de gebeele sebors aan, soms boofdzakelijk bet motorisch gedeelte, soms bet psycho- sensorieel of psycho-sensibel gedeelte en geeft dan de daaraan Geantwoordende symptomen, soms ook de diverse psycbische i.c. de niet direct met de reflexboog verbonden gedeelte der bersenen voornamelijk dus [dan? I de voorboofdsebors. De laatste zijn die vormen, waar de epilepsie duidelijk een psycbische ziekte is, met langdurige balf bewustelooze toestanden, soms petit mal, soms niet, met waandenkbeelden, vervolgingsideeen, soms maar lang niet altijd dementie, zeer dikwijls degeneratieve amoreele symptomen enz. Deze laatste vormen bebben bebbe veel overeenkomst met de periodieke en circulaire psychosen, en omgekeerd neemt men waar dat plotseling er gevallen [zijn] waar men een circulaire of periodiscbe krankzinnigbeidsvorm met zekerbeid mag aannemen dat een of meer epileptische of epileptoide aanvallen optreden. Wanneer dus na petit mal somtijds snel dementie optreed geloof ik dat dat zijn oorzaak vindt in een [...? I aandoening der zuiver psycbische spbeer, dan beboeven de krampsymptomen [...? I niet sterk op den voorgrond te treden; maar men beeft dan een epilepsie die na verwant is aan psycbosen, die de oorzaak van een dementie kunnen zijn. Bij periodieke psycbosen komen ook aanvallen voor met gebeel of gedeeltelijk verlies van berinnering voor de tijd van den aanval. Na petit mal volgt niet zoo dikwijls als men wel zegt dementie, maar meer een toestand die enige overeenkomst beeft met cbronische onanie en karakterontaarding. Ik zou je natuurlijk nog een massa kunnen scbrijven, mijne opvattingen wijken soms wel van de gangbare opinies af, later boop ik een kliniseb overzicht te geven. Over een week of zes denk ik je eens een bezoek in Rotterdam te komen brengen; dan neem ik waarsebijnlijk mijn meisje mee en geef je daar nog wel bericht van.-

Nu vele groeten 
Op 20 september 1899 aanvaardt Jelgersma als eerste in ons land in dat ambt een benoeming tot hoogleraar psychiatrie aan de Rijksuniversiteit van Leiden. De neurologie maakt dan nog integraal deel uit van de psychiatrie. Als hoogleraar is Jelgersma ook een van de eerste aanhangers in ons land van de door Sigmund Freud in Wenen ontwikkelde psychoanalyse. In IgII brengt Jelgersma zijn driedelige Leerboek de psychiatrie uit. Na zijn emeritaat en het overlijden van zijn echtgenote in 1930 verschijnt een jaar later nog zijn opus magnum Atlas anatomicum cerebri humani, een verzameling van schitterende afbeeldingen van door hem vervaardigde coupes van het menselijk brein.

\section{Ideeën over de pathogenese van epilepsie}

In zijn brief lezen we dat Jelgersma een psychische oorzaak veronderstelde van epilepsie, uitgaande van een plaatselijk verdikte hersenschors. Daarbij zouden ook een tweetal van de basale hersenkernen, namelijk het corpus striatum en de nucleus lentiformis, een rol spelen. Opmerkelijk is dat hij hierover in zijn artikel in het Tijdschrift van 7 januari I888 in het geheel niet rept.

Jelgersma stelde in zijn brief met name een klinische verwantschap vast tussen epilepsie en psychosen. Als argument daarvoor voerde hij de bij epilepsie postictaal optredende psychische verschijnselen aan, alsook de bij deze aandoening voorkomende dementering en karakterveranderingen zoals 'egoïsme'.

Ook voor wat we nu partiële aanvallen noemen, gepaard gaande met motorische of sensorische symptomen, zag Jelgersma een psychische oorzaak. De frontale hersenschors zou daarbij verantwoordelijk zijn voor het optreden van een verlaagd bewustzijn, petit malaanvallen, paranoïde waangedachten, dementie en/of 'amorele' symptomen. Jelgersma opperde in zijn brief nog een relatie tussen deze laatste verschijnselen en wat we nu een bipolaire stoornis zouden noemen. Na petit mal zou minder vaak dementering optreden maar 'meer een toestand die overeenkomst heeft met chronische onanie en karakterontaarding'.

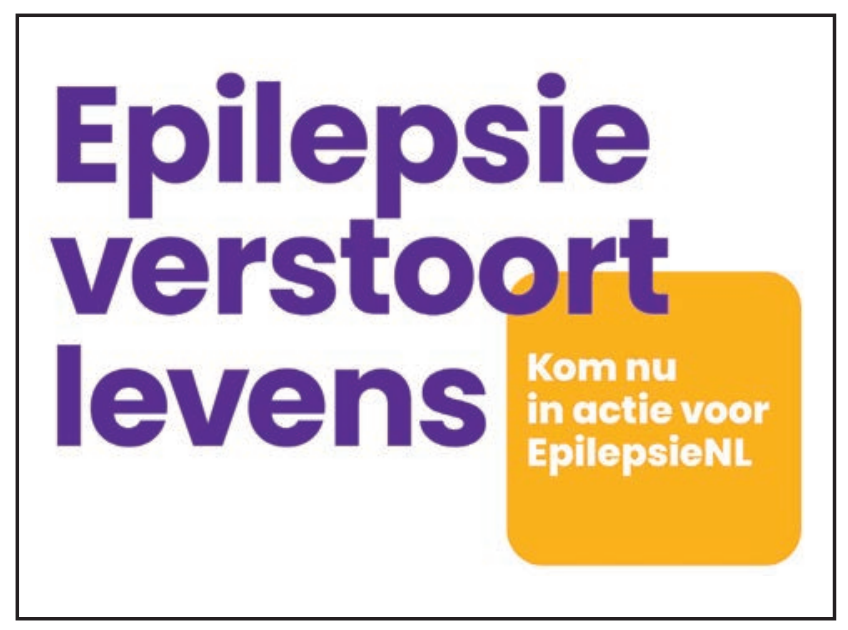

Jelgersma's latere gedachten over de oorzaken en kliniek van epilepsie vonden tevens hun weg naar het Nederlandsch Tijdschrift voor Geneeskunde. Zo verscheen in februari I8go als Wetenschappelijke Mededeeling 'De anatomische veranderingen der hersenen bij epilepsie'. Zijn op 4 juli I899 in Arnhem in de algemene vergadering van de Nederlandsche Maatschappij tot bevordering van de Geneeskunst gehouden voordracht 'Over de differentieele diagnose tusschen hysterie en epilepsie' werd drie weken later in het Tijdschrift afgedrukt. In deze lezing heeft Jelgersma duidelijk afstand genomen van zijn in I888 geventileerde gedachten over de aetiologie van epilepsie:

'Doorgaand verschillend van het hysterisch insult is, dat er bij epilepsie nooit een psychisch motief voor het insult aanwezig is en dat er dus ook nooit sprake van kan zijn, dat men een psychische oorzaak in het acces kan terug vinden. Alle bewegingen van het epileptisch insult dragen een organisch karakter en drukken dus niet een of ander psychisch proces uit.'

In 1908 verschenen in het Tijdschrift van Jelgersma's hand nog de klinische lessen 'Het epileptisch insult' en 'Hysterie en epilepsie'. En in rgro 'Dementievormen', waarin hij een alinea wijdde aan de bij epilepsie optredende dementering.

\section{Conclusie}

In zijn brief uit I888 verwisselt Jelgersma oorzaak en gevolg van epilepsie. Als verklaring hiervan kan worden gegeven dat hij als jong arts in Meerenberg alleen nog maar ervaring heeft met de pathologisch-anatomische, postmortale bevindingen bij epileptici. In zijn in I899 gehouden voordracht in Arnhem blijkt hij enkele maanden voor de aanvaarding van zijn Leidse hoogleraarschap zijn mening diametraal te hebben bijgesteld. Wat hij eerder als oorzaak van epilepsie veronderstelt, ziet hij dan als gevolg daarvan. Dit kennelijk vanuit zijn voortschrijdende inzicht nadat hij in zijn latere werkzaamheden ook de klinische verschijnselen van epilepsie heeft leren kennen.

\section{Referenties}

Carp, EADE (I943) Jelgersma Leven en werken van een verdienstelijk Nederlander, Lochem.

Jelgersma, G (I888) Over de pathogenese der epilepsie, Ned Tijdschr Geneeskd. I888;32:I-II.

Jelgersma, G (I899) Over de differentieele diagnose tusschen hysterie en epilepsie, Ned. Tijdschr Geneeskd. I899;43: 22I-232.

Van Gein, Jan en Gijselhart, Joost P (20II) Jelgersma en zijn kliniek, Ned Tijdschr Geneesk. 20II;155:A3219. 